\title{
Development of TIF for transaction cost allocation in deregulated power system
}

\author{
Noolu.Narendra Reddy ${ }^{1}$, Kurakula.Vimala Kumar ${ }^{2}$ \\ P.G. Scholar, Department of EEE, JNTUA College of Engineering Pulivendula, Andhra Pradesh, India ${ }^{1}$ \\ Asst. professor, Department of EEE, JNTUA College of Engineering Pulivendula, Andhra Pradesh, India ${ }^{2}$
}

\begin{abstract}
In deregulated power system due to the increase of power transactions in transmission open access the transmission cost allocation is one of the major problems. For each transaction the Transaction Impact Factors (TIFs) are developed for the allocation of the transmission transaction costs. The transmission Impact Factor gives the information about the real power flow in the transmission lines with the transacted power. This logical method provides the impact of the line flows without running power flow solutions when the amount of transacted power changes in real time. This proposed method is evaluated by considering bilateral and multilateral transactions. The results coming from the proposed method is compared with Megawatt Modulus (MM) method on sample six bus and IEEE 30 bus system.
\end{abstract}

Key words: Deregulation, Cost allocation, Transmission Impact Factors, Bilateral transaction, Multilateral transaction.

\section{I.INTRODUCTION}

In integrated system, wheeling transactions have been accounted for a small portion of the overall transmission network capacity usage. However, recent trends towards unbundling of electric services have resulted in renewed interest in pricing of transmission services, particularly to the wheeling transactions. The cost components [1] for providing transmission services are operating cost, opportunity cost, reinforcement cost and existing system cost. Depending upon the type of the transmission transaction one or all the above mentioned cost components are included in the pricing scheme. Transmission pricing is broadly classified [2] as embedded (rolled-in) transmission pricing, marginal transmission pricing and composite transmission pricing. In embedded pricing (Postage Stamp Method, Contract Path Method, MW-Mile Method) the cost for building infrastructure, operating and maintenance costs are included. Marginal cost of a transmission transaction is defined as the cost of accommodating a marginal increase (of say one $\mathrm{KW}$ ) in the transacted power. Otherwise the marginal transmission pricing is nothing but a cost allocated to the new customer. Composite pricing scheme include the features of above two methods.

All type of usage based transmission cost allocation schemes require accurate knowledge of change in power flowcaused by the transaction. The impact of power flow in the line can be calculated by electricity tracing methods $[3,4]$. A topological approach to find the share of each generator and load in every power flow is provided in [3]. Thistopological generation and load distribution factors are always positive but it requires inverse of a matrix of theorder equal to the network nodes. Contribution of generator and load on the line flow can also be determined bydefining set of domains, commons and links [4]. The transmission cost allocation method based on equivalentbilateral exchanges [5] states that each demand is supplied by a fraction of each generator uniformly divided amongall generators. But this method uses dc power flow solution. A methodology based on circuit theory [6] uses thecontributions of the nodal currents to line power flows to apportion the usage of the lines.

Copyright to IJIREEICE
Different cases of-mile method is discussed in [7]. In order to meet the system reliability, stability and security criteria all the market participants have to pay for the actual capacity use and for the additional reserve [8]. Megawatt Modulus (MM) method ensures recovery of all transmission costs by replacing the circuit capacities by the sum of absolute power flows caused by all agents.

Different usage based transmission cost allocation methods are summarized in [9] and concludes that fixed transmission costs determined by different algorithms are quite similar. The choice of algorithms used for the evaluation of transmission usage depends mainly on the requirements and the market structures. The impact of power flow in all the line in a network due to particular transaction is usually determined by power flow solution. In conventional methods, the line flow impacts are calculated by executing repeated power flows by Newton Raphson (NR) method for varying magnitude of power transacted which is a time consuming process. To simplify the evaluation of power flow impact, the line flows are related with the power contract magnitude by the factor called Transaction Impact Factor (TIF) . Once the TIF is evaluated, then the power flow impacts can be obtained by multiplying it with the transacted real power between the parties.

\section{DERIVATION OF TRANSACTION IMPACT FACTOR}

The sensitivity of real power flow in the line $m-n$ when one megawatt of power is transacted between seller bus $i$ andbuyer bus $j$ is known asTIF $F_{m-n}^{i j}$. It means that, if one megawatt of power is injected at bus $i$ and extracted at bus $j$ then $T I F^{i j}{ }_{m-n}$ is the power flow impact of the line $m-n$ due to this transaction. The change in power flow (MW) in linem- $n$ can be written as the sum of impact of power flow due to all sellers involved in that transaction as,

$$
\Delta P_{m-n}=\sum_{i=1}^{n b} \Delta P_{m-n}^{i}
$$


where, $\Delta P_{m-n}^{i}$ is the impact of power flow in line $m-n$ due to $i^{\text {th }}$ seller and $n s$ is the number of sellers involved inthat transaction. Further the impact of power flow $\Delta P_{m-n}^{i}$ can be written as sum of impact due to transactionbetween seller bus $i$ and buyer bus $j\left(\Delta P_{m-n}^{i}\right)$

$$
\Delta P_{m-n}=\sum_{i=1}^{n b} \Delta P_{m-n}^{i j}
$$

Where $n b$ is the number of buyers, Equation (2) is multiplied and divided by the magnitude of real powertransacted $\left(P_{i}^{j}\right)$ between seller bus $i$ and buyer bus $j$

$$
\Delta P_{m-n}^{i}=\sum_{i=1}^{m} \frac{\Delta P_{m-n}^{i}}{P_{i}^{j}} * P_{i}^{j}
$$

TIF can be defined as the ratio of change in real power flow in the line including the transaction to the magnitude ofthe corresponding transacted power. It is given as,

$$
T I F_{m-n}^{i j}=\frac{\Delta P_{m-n}^{i j}}{P_{i}^{j}}
$$

Then (3) becomes,

$$
\Delta P_{m-n}^{i}=\sum_{j=1}^{n b} T I F_{m-n}^{i j} * P_{i}^{j}
$$

The change in real power flow due to multilateral transactions is,

$$
\Delta P_{m-n}=\sum_{i=1}^{n s} \sum_{j=1}^{n b} T I F_{m-n}^{i j} * P_{i}^{j}=\sum_{t} T I F_{m-n}^{i j} * P_{i}^{j}
$$

\section{III.TRANSACTION COST ALLOCATION}

A. Wheeling Charges

The suggested method evaluates the change in power flow in all transmission lines when a new transaction isintroduced in the system. Wheeling charges to the transaction are then allocated in proportion to the ratio of itsabsolute value of actual facility usage and the magnitude of total power flows. The proposed allocation rule due tobilateral transaction is given as follows,

$$
W C_{t}=\sum_{\text {Allines }} C_{m-n} \frac{\left|T I F_{m-n}^{i j}\right| * P_{i}^{j}}{\left|P_{m-n}^{0}\right|+\left|T I F_{m-n}^{i j}\right| * P_{i}^{j}}
$$

Where $W C_{t}$ is wheeling charge $(\$ / \mathrm{hr})$ for transaction $t$, $C_{m-n}$ is charge for transaction facility $m-n$ and $P_{m-n}^{0}$ is base case real power flow.For multilateral transaction, total change in power flow due to all transaction can be obtained by (6).

Wheeling Charge $(\$ / \mathrm{hr})$ for multilateral transaction can be written as

B.Cost allocation to users

In bilateral transaction, the costs have to be allocated to both seller and buyer according to their usage of the network. The proportional sharing of the cost to seller and buyer will differ for different structure. For the case of $50 \%$ share to seller and $50 \%$ share to buyer, the seller Wheeling Charge and Buyer Wheeling Charge in $\$ / \mathrm{hr}$ for thetransaction $t$ are given by,

$$
S W C_{t}=\frac{W C_{t}}{2} \text { and } B W C_{t}=\frac{W C_{t}}{2}
$$

Similarly for $30 \%$ share to seller and $70 \%$ share to buyer the following formulae are used,

$$
S W C_{t}=\frac{3 * W C_{t}}{2} \text { and } B W C_{t}=\frac{7 * W C_{t}}{2}
$$

Also for multilateral transaction, the cost has to be allocated to individual seller and buyer based on their usage ofthe transmission facilities. For this, the usage of transmission line by individual seller and buyer has to beseparated. The usage of line $m-n$ by the seller at bus $i$ due to multilateral transaction $\Delta P_{m-n}^{i}$ is calculated by (5),Similarly, the usage of line $m-n$ by the buyer at bus $\mathrm{j}$ due to multilateral transaction is given by,

$$
\Delta P_{m-n}^{j}=\sum_{i=1}^{n s} T I F_{m-n}^{i j} * P_{i}^{j}
$$

The wheeling charge for seller $i$ for using all the lines $S W C_{i}(\$ / \mathrm{hr})$ and the wheeling charge for buyer $j$ for usingall the lines $B W C_{j}$ are given by,

$$
\begin{aligned}
S W C_{t} & =\sum_{\text {Allines }} r_{m-n} * \Delta P_{m-n}^{i}(12 a) \\
B W C_{t} & =\sum_{\text {Allines }} r_{m-n} * \Delta P_{m-n}^{j}(12 b)
\end{aligned}
$$

Where, $r_{m-n}$ is the charge rate of line $m-n$ in $\$ / M W h r$ which is obtained by dividing the cost for each line by total usage of that line by all the transactions.

$$
r_{m-n}=\frac{C_{m-n}}{\left|P_{m-n}^{0}\right|+\left|T I F_{m-n}^{i j}\right| * P_{i}^{j}}
$$

The proportional sharing of the cost to seller and buyer for the case of 50\% share to seller and $50 \%$ share tobuyer the cost is evaluated by following equations,

$$
S W C_{t}=\frac{S W C_{t}}{2} \text { and } B W C_{t}=\frac{B W C_{t}}{2}
$$

Similarly for $30 \%-70 \%$ sharing policy the following formulae are used, 


$$
S W C_{t}=\frac{3 * S W C_{t}}{2} \text { and } B W C_{t}=\frac{7 * B W C_{t}}{2}
$$

\section{IV.ALGORITHM}

Step1. Read system bus data and line data.

Step2. Run base case power flow solution.

Step3. Consider bilateral transaction between seller $i$ and buyer $j$, or multilateral transaction between group ofsellers and buyers. Calculate TIF values using (4).

Step4. The change in power flow due to power contract is evaluated by (6). The value of $n s$ and $n b$ are equal to 1 forbilateral transaction in (6).

Step5. Cost of transmission transactions for bilateral transaction is calculated by (7).

Step6. If multilateral transaction is considered then find cost of transmission transaction by (8).

Step7. The transmission usage cost allocated to seller $S W C_{t}$ and buyer $B W C_{t}$ for the use of all lines is calculated byusing (9) or (10) for bilateral transaction.

Step8. If multilateral transaction is considered then the transmission usage cost allocated to seller $S W C_{t}$ and buyer $B W C_{t}$ for the use of all lines is evaluated by using (14) or (15).

\section{RESULTS AND DISCUSSION}

In this paper, an analytical method is proposed using TIF for the calculation of transmission transaction cost andthe results are compared with conventional Megawatt Modulus (MM) method [8]. The proposed method is tested onsample six bus system and IEEE 30 bus system. The program is developed in MATLAB 7.0 environment.

\section{A. Six bus system}

The sample six bus system [10] consists of three generators, three loads and eleven transmission lines. The totalsystem demand is $210 \mathrm{MW}$. The first bus is considered as slack bus. One bilateral transaction $\mathrm{T} 1$ and a multilateraltransaction $\mathrm{T} 2$ with two cases are considered for this system.

\section{(1) Bilateral transaction (T1) of $20 \mathrm{MW}$ between seller bus 2 and buyer bus 5}

TIF values are obtained for the above transaction by (4). The TIF values for transaction $\mathrm{T} 1$ and change in powerflow due to this transaction are given in Table I. Once the transaction impact factor for any transaction is known thenit is easy to calculate the change in power flow due to that transaction by multiplying TIF with the magnitude ofpower transacted as given in (6).

The actual power flow after including particular transaction is obtained by adding the change in power flow dueto that transaction with the base case power flow.
TABLE I. TIF VALUES AND CHANGE IN POWER FLOW FOR 6 BUS SYSTEM

\begin{tabular}{|l|l|l|}
\hline Line $\boldsymbol{m}-\boldsymbol{n}$ & \multicolumn{1}{|c|}{$\begin{array}{l}\text { TIF } \\
\text { values }\end{array}$} & $\begin{array}{l}\text { Change in Power } \\
\text { flow (MW) }\end{array}$ \\
\hline $1-2$ & 0.1430 & 2.8601 \\
\hline $1-4$ & 0.0655 & 1.3106 \\
\hline $1-5$ & 0.1490 & 2.9796 \\
\hline $2-3$ & 0.1663 & 3.3263 \\
\hline $2-4$ & 0.1359 & 2.7181 \\
\hline $2-5$ & 0.2862 & 5.7239 \\
\hline $2-6$ & 0.1884 & 3.7674 \\
\hline $3-5$ & 0.1492 & 2.9831 \\
\hline $3-6$ & 0.0852 & 1.7043 \\
\hline $4-5$ & 0.1856 & 3.7114 \\
\hline $5-6$ & 0.1689 & 3.3775 \\
\hline
\end{tabular}

For the transaction T1, the actual power flow in all the lines obtained by proposed method is compared with theNewton Raphson (NR) power flow solution values and they are given in Table II. Power flow in each line obtained byboth methods is almost same. In proposed method, no need to run the power flow solution repeatedly. Theadvantage of the proposed method is best being explained with the help of multilateral transaction in the followingsections.

\section{TABLE II. POWER FLOW COMPARISON FOR T1}

\begin{tabular}{|l|l|l|}
\hline \multirow{2}{*}{$\begin{array}{l}\text { Line } \\
m-n\end{array}$} & \multicolumn{2}{|l|}{ Power flow (MW) } \\
\cline { 2 - 3 } & $\begin{array}{l}\text { NR } \\
\text { method }\end{array}$ & $\begin{array}{l}\text { Proposed } \\
\text { method }\end{array}$ \\
\hline $1-2$ & 26.0624 & 26.7345 \\
\hline $1-4$ & 42.8631 & 43.3619 \\
\hline $1-5$ & 39.8136 & 39.6541 \\
\hline $2-3$ & 6.5720 & 6.2970 \\
\hline $2-4$ & 36.9897 & 37.3142 \\
\hline $2-5$ & 21.5933 & 21.7363 \\
\hline $2-6$ & 30.1586 & 30.5997 \\
\hline $3-5$ & 23.1126 & 23.1935 \\
\hline $3-6$ & 43.3976 & 43.0723 \\
\hline $4-5$ & 7.1846 & 7.8308 \\
\hline $5-6$ & 1.7576 & 1.7137 \\
\hline
\end{tabular}

The total wheeling charges for transaction $\mathrm{T} 1$ is obtained by (7). The cost for each line $\mathrm{Cm}-n$ is assumed as thevalue of line reactance for that line multiplied by $1000 \mathrm{in} \$ / \mathrm{hr}$. The total wheeling charge for $\mathrm{T} 1$ is $731.4 \$ / \mathrm{hr}$. Thisamount is allocated among the seller and buyer by two cases of cost sharing policy as per Table III based on (9) and(10). Also the results of proposed method are compared with Megawatt Modulus (MM) method [8]. The MM methodneeds two power flow solutions, one is without transaction and the other is with the transaction to find the changein power flow. Total wheeling charges obtained by both the methods are almost similar. 


\begin{tabular}{|c|c|c|c|c|}
\hline $\begin{array}{l}\text { Sharing } \\
\text { policy (\%) }\end{array}$ & Method & $\begin{array}{l}\text { Cost for } \\
\text { Seller at } \\
\\
\text { bus } 2 \\
(\$ / \mathrm{hr})\end{array}$ & \begin{tabular}{|l|}
$\begin{array}{l}\text { Cost for } \\
\text { Buyer at }\end{array}$ \\
bus 5 \\
$(\$ / \mathrm{hr})$ \\
\end{tabular} & $\begin{array}{l}\text { Total cost } \\
(\$ / \mathrm{hr})\end{array}$ \\
\hline \multirow{2}{*}{$50-50$} & Proposed & 361.3136 & 361.3136 & 722.6273 \\
\hline & MM & 366.2 & 366.2 & 732.4 \\
\hline \multirow{2}{*}{$30-70$} & Proposed & 216.7882 & 505.8391 & 722.627 \\
\hline & MM & 219.7 & 512.7 & 732.4 \\
\hline
\end{tabular}

(2) Multilateral transaction T2 - case 1

A Multilateral transaction T2 of case 1 is considered for the six bus system as per Table IV. The prefix $S$ refersseller bus and $\mathrm{B}$ refers buyer bus. There are two seller buses 1, 2 and two buyer buses 4, 5 involved in thistransaction. Buyer at bus 4 is agreed to buy $10 \mathrm{MW}$ from seller 1 and $5 \mathrm{MW}$ from seller 2 to meet its demand of $15 \mathrm{MW}$. Similarly Buyer at bus 5 is agreed to buy $5 \mathrm{MW}$ from seller 1 and $10 \mathrm{MW}$ from seller 2 to meet its demand of $15 \mathrm{MW}$. Total of $30 \mathrm{MW}$ is transacted in this multilateral transaction.

\section{TABLE IV. MULTILATERAL TRANSACTION T2 - CASE 1}

\begin{tabular}{|c|c|c|c|}
\hline & \multicolumn{2}{|c|}{$\begin{array}{l}\text { Transaction i } \\
\text { MW }\end{array}$} & \multirow{2}{*}{$\begin{array}{c}\text { Total } \\
\text { Generation } \\
\text { (MW) }\end{array}$} \\
\hline & To B4 & ToB5 & \\
\hline From S1 & 10 & 5 & 15 \\
\hline From S2 & 5 & 10 & 15 \\
\hline $\begin{array}{l}\text { Total Load } \\
\text { (MW) }\end{array}$ & 15 & 15 & 30 \\
\hline
\end{tabular}

This multilateral transaction includes four transactions. The TIF for all these transactions are calculated and givenin Table $\mathrm{V}$. These factors are constant for any possible magnitude power transacted between these sellers andbuyers. The TIF values may be positive or negative depending upon the power flow direction. But in calculatingWheeling charges, the magnitude of TIF is considered. For any possible combination of power contracts the line flowimpacts can be easily obtained. The change in power flow for this multilateral transaction is given in Table VI. Herethere are two $n s$ and two $n b$. Actual power flow in each line by proposed method is calculated by summing up thischange in power flow with the base case power flow. The total wheeling charge for multilateral transaction evaluatedby (8) is $962.8 \mathrm{\$} / \mathrm{hr}$. This cost is allocated among the sellers and buyers based on their usage of the transmission facility to carry out this transaction. The cost for two seller buses and two buyer buses are allocated by (14) and (15)and given in Table VII
TABLE V. TIF VALUES FOR T2 - SAMPLE 6 BUS SYSTEM

\begin{tabular}{|c|c|c|c|c|}
\hline \multirow{2}{*}{$\begin{array}{l}\text { Line } \\
m-n\end{array}$} & \multicolumn{2}{|c|}{ Seller at bus 1} & \multicolumn{2}{|c|}{ Seller at bus 2} \\
\hline & $\begin{array}{l}\text { Buyer at } \\
\text { bus } 4\end{array}$ & $\begin{array}{l}\text { Buyer at } \\
\text { bus } 5\end{array}$ & $\begin{array}{l}\text { Buyer at } \\
\text { bus } 4\end{array}$ & $\begin{array}{l}\text { Buyer at } \\
\text { bus } 5\end{array}$ \\
\hline $1-2$ & 0.3039 & 0.2371 & -0.2376 & -0.1672 \\
\hline $1-4$ & 0.4222 & 0.1212 & -0.0092 & -0.1127 \\
\hline $1-5$ & 0.1283 & 0.2458 & -0.1968 & 0.1098 \\
\hline $2-3$ & -0.0239 & 0.1224 & 0.0351 & 0.1881 \\
\hline $2-4$ & 0.2761 & 0.4264 & 0.4385 & 0.0475 \\
\hline $2-5$ & -0.0887 & 0.0968 & -0.0317 & 0.2526 \\
\hline $2-6$ & -0.0733 & 0.0388 & -0.0589 & 0.1574 \\
\hline $3-5$ & -0.1349 & -0.0746 & -0.1827 & 0.1077 \\
\hline $3-6$ & -0.1049 & -0.2350 & -0.2141 & -0.1359 \\
\hline $4-5$ & -0.1277 & 0.1798 & 0.1384 & 0.1744 \\
\hline $5-6$ & 0.0187 & -0.1118 & -0.0455 & -0.1668 \\
\hline
\end{tabular}

TABLE VI. CHANGE IN POWER FLOW FOR T2-CASE1

\begin{tabular}{|l|l|l|l|l|}
\hline \multirow{2}{*}{ Line } & \multicolumn{2}{|c|}{ Seller at bus 1 } & \multicolumn{2}{c|}{ Seller at bus 2 } \\
\cline { 2 - 5 } $\boldsymbol{m - n}$ & & & & \\
\hline & Buyer at & Buyer at & Buyer at & Buyer at \\
\hline $1-2$ & 3.0393 & 1.1857 & -1.1881 & -1.6725 \\
\hline $1-4$ & 4.2217 & 0.6062 & -0.0459 & -1.1266 \\
\hline $1-5$ & 1.2828 & 1.2288 & -0.9841 & 1.0981 \\
\hline $2-3$ & -0.2388 & 0.6122 & 0.1755 & 1.8814 \\
\hline $2-4$ & 2.7608 & -2.1320 & 2.1927 & 0.4749 \\
\hline $2-5$ & -0.8875 & 0.4839 & -0.1587 & 0.5260 \\
\hline $2-6$ & -0.7327 & 0.1942 & -0.2945 & 1.5736 \\
\hline $3-5$ & -1.3486 & -0.3728 & -0.9133 & 1.0774 \\
\hline $3-6$ & -1.0494 & -1.1750 & -1.0707 & -1.3586 \\
\hline $4-5$ & -1.2771 & 0.8988 & -0.6919 & 1.7444 \\
\hline $5-6$ & 0.1874 & -0.5588 & -0.2274 & -1.6682 \\
\hline
\end{tabular}

The cost for S2 and B5 are high because the usage of the transmission network by these parties are more byproviding more impact in line flows. The same pattern of results is obtained in MM method also. But the MM methodneeds five power flow solutions to evaluate the change in power flow for this multilateral transaction. One for basecase and four for transaction cases with specified magnitude. If any one of the transaction magnitude changes thenpower flow solution has to be done again.

\section{TABLE VII. COST ALLOCATION FOR T2 - CASE 1 - 6 BUS SYSTEM}

\begin{tabular}{|c|c|c|c|c|c|c|c|c|}
\hline & \multicolumn{4}{|c|}{$50 \%-50 \%$ share } & \multicolumn{4}{|c|}{$30 \%-70 \%$ share } \\
\hline & \multicolumn{2}{|c|}{$\begin{array}{l}\text { Proposed } \\
\end{array}$} & \multicolumn{2}{|c|}{$\mathrm{mm}$} & \multicolumn{2}{|c|}{ Proposed } & \multicolumn{2}{|c|}{$\mathrm{Mm}$} \\
\hline & $\begin{array}{l}S W C_{(S)} \\
\text { hir) }\end{array}$ & $\begin{array}{c}B W C_{(}(\$ / h / h \\
\mathrm{r})\end{array}$ & 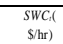 & $\begin{array}{c}B W C_{(S / / h} \\
\mathrm{r})\end{array}$ & $\begin{array}{c}S W C_{(S / h /} \\
\mathrm{r})\end{array}$ & $\begin{array}{c}B W C_{C}(\$ \\
/ h \mathrm{hr}\end{array}$ & $S W C_{1}(S / h r$ & $\begin{array}{c}B W C,(S / \mathrm{h} \\
\mathrm{r}\end{array}$ \\
\hline S1 & 196.1 & .. & 198.5 & -- & 117.6 & .. & 119.1 & .. \\
\hline S2 & 280.6 & - & 283.3 & - & 168.3 & $\ldots$ & 170.0 & - \\
\hline B4 & -- & 148.4 & -. & 150.3 & - & 207.8 & - & 210.5 \\
\hline B5 & .- & 33.6 & 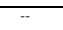 & 331.5 & 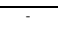 & 467.0 & $\ldots$ & 464.0 \\
\hline $\begin{array}{l}\text { Total } \\
\text { Whee }\end{array}$ & 476.7 & 482.0 & 481.8 & 481.8 & 286.0 & 674.8 & 289.1 & 674.5 \\
\hline $\begin{array}{l}\text { ling } \\
\text { charg } \\
\text { e } \\
\text { (\$/lir) }\end{array}$ & & & & & & & & \\
\hline
\end{tabular}


(3) Multilateral transaction T2 - case 2

To explain the advantage of proposed method one more transaction case is considered for the same multilateraltransaction between seller buses 1,2 and buyer buses 4, 5 with different power level as per Table VIII. Here total of $40 \mathrm{MW}$ is transacted between the parties. Buyer at bus 4 is agreed to buy $10 \mathrm{MW}$ from seller 1 and $10 \mathrm{MW}$ fromseller 2 to meet its demand of 20MW. Similarly Buyer at bus 5 is agreed to buy 15 MW from seller 1 and $5 \mathrm{MW}$ fromseller 2 to meet its demand of 20 MW

\section{TABLE VIII. MULTILATERAL TRANSACTION T2 -} CASE 2

\begin{tabular}{|c|c|c|c|}
\hline & \multicolumn{2}{|c|}{ Transaction in MW } & \multirow{2}{*}{$\begin{array}{c}\text { Total } \\
\text { Generation } \\
\text { (MW) }\end{array}$} \\
\hline & To B4 & To B5 & \\
\hline From S1 & 10 & 15 & 25 \\
\hline From S2 & 10 & 5 & 15 \\
\hline $\begin{array}{c}\text { Total Load } \\
\text { (MW) }\end{array}$ & 20 & 20 & 40 \\
\hline
\end{tabular}

For transaction case 2 of T2, since the parties involved in the transaction remains same, the TIF factors are alsosame as in Table $\mathrm{V}$. The change in power is obtained by (6) is given in Table IX. But in MM method, the power flowsolution shouldbe repeated for every change in power transacted. The actual power flow obtained in this case alsosimilar to that of NR method. The total cost allocated for multilateral transaction of $40 \mathrm{MW}$ is about $1156.6 \$ / \mathrm{hr}$. The transmission usagecharges for different percentage of sharing in transmission cost for seller and buyer is evaluated and given in Table X.In case of 50\%-50\% share to seller and buyer, the buyer will get benefited and whereas in the case of $30 \%-70 \%$ share, the consumer pays maximum share, so the seller will get benefited.

TABLE IX. CHANGE IN POWER FLOW FOR T2CASE 2

\begin{tabular}{|c|c|c|c|c|}
\hline $\begin{array}{c}\text { Line } \\
\boldsymbol{m}-\boldsymbol{n}\end{array}$ & \multicolumn{2}{|c|}{ Seller at bus 1 } & \multicolumn{2}{c|}{ Seller at bus 2 } \\
\cline { 2 - 5 } & $\begin{array}{c}\text { Buyer at } \\
\text { bus 4 }\end{array}$ & $\begin{array}{c}\text { Buyer at } \\
\text { bus 5 }\end{array}$ & $\begin{array}{c}\text { Buyer at } \\
\text { bus 4 }\end{array}$ & $\begin{array}{c}\text { Buyer at } \\
\text { bus 5 }\end{array}$ \\
\hline $1-2$ & 3.0393 & 4.9679 & -1.6974 & -1.1765 \\
\hline $1-4$ & 4.2217 & 3.8355 & 0.9085 & -1.0606 \\
\hline $1-5$ & 1.2828 & 5.5699 & -1.0320 & 0.0777 \\
\hline $2-3$ & -0.2388 & 1.9235 & 0.3817 & 0.9215 \\
\hline $2-4$ & 2.7608 & -3.3236 & 5.9440 & -0.5332 \\
\hline $2-5$ & -0.8875 & 2.4642 & 0.1770 & 1.0136 \\
\hline $2-6$ & -0.7327 & 1.6442 & -0.0705 & 0.5241 \\
\hline $3-5$ & -1.3486 & 1.2059 & -0.6789 & -0.0393 \\
\hline $3-6$ & -1.0494 & -1.4451 & -1.0991 & -1.1998 \\
\hline $4-5$ & -1.2771 & 2.7635 & -1.3595 & 0.8572 \\
\hline $5-6$ & 0.1874 & -1.5930 & -0.4110 & -0.8564 \\
\hline
\end{tabular}

Copyright to IJIREEICE
TABLE X. COST ALLOCATION FOR T2 CASE $2-6$ BUS SYSTEM

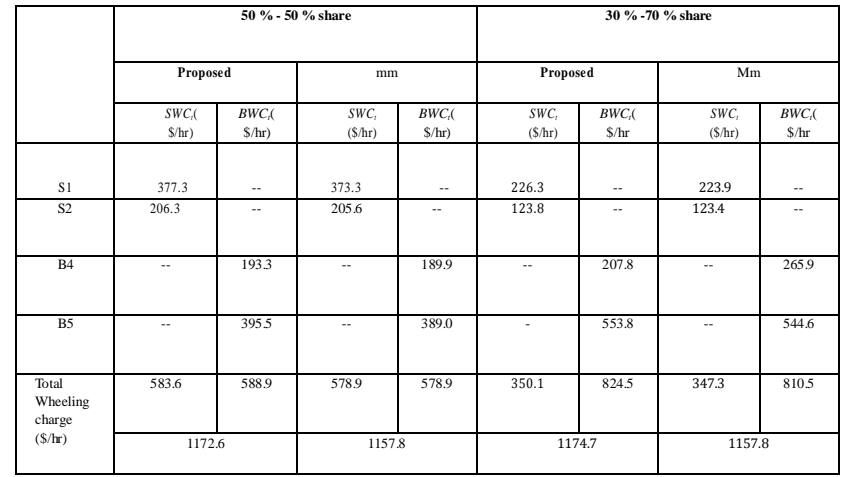

B. IEEE 30 bus system

The numerical data for IEEE 30 bus system is taken from [11]. In this system there are 6 generators, 24 loads and 41 transmission lines with the total demand of $283.4 \mathrm{MW}$. Generator connected at bus 1 is considered as slack. Amultilateral transaction with two cases is considered for this system.

(1) Multilateral transaction - case 1

Multilateral transaction involving three seller buses 2,5,8 and three buyer buses 12,16,29 is considered as given in Table XI. Total of $50 \mathrm{MW}$ is transacted in this multilateral transaction. S8 has highest generation and $\mathrm{B} 12$ has highest load in the transaction considered. The TIF for all the nine transactions is calculated as explained earlier.

TABLE XI. MULTILATERAL TRANSACTION CASE 1 FOR IEEE30 BUS SYSTEM

\begin{tabular}{|c|c|c|c|c|}
\hline & \multicolumn{3}{|c|}{ Transaction in MW } & $\begin{array}{c}\text { Total } \\
\text { Generation } \\
\text { (MW) }\end{array}$ \\
\cline { 2 - 4 } & To B12 & To B16 & To B29 & 12 \\
\hline From S2 & 5 & 2 & 5 & 15 \\
\hline From S5 & 5 & 8 & 2 & 23 \\
\hline From S8 & 10 & 3 & 10 & 50 \\
\hline $\begin{array}{c}\text { Total Load } \\
\text { (MW) }\end{array}$ & 20 & 13 & 17 & \\
\hline
\end{tabular}

The actual line flows in all the lines due to contract case 1, by proposed method and NR method are compared and multilateral transaction is within the line capacity. The aboveconsidered multilateral transactions provide highest impact on flow in first line 1-2 (72.13 MW) because generationat bus 1 including base case is the maximum of all. The line number 9,30 and 37 has least impact of power flowbecause these lines are relatively away from the buses that involved in the considered transaction.

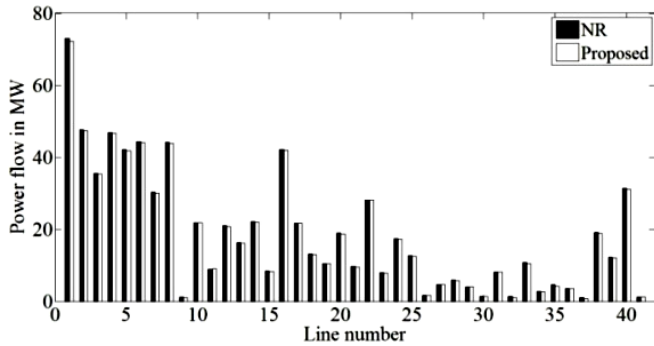

Fig. 1. Power flow by proposed method for transaction case 1 - IEEE 30 bus system. 
shown in Fig.1. For all the lines the flow due to this

(2) Multilateral transaction - case 2

In the multilateral transaction case, eight transactions are considered as given in Table XII. Total generation in $8^{\text {th }}$ bus is the highest of $30 \mathrm{MW}$, but in case 1 its value is 23 MW.

TABLE XII. MULTILATERAL TRANSACTION CASE 2 FOR IEEE30 BUS SYSTEM

\begin{tabular}{|c|c|c|c|c|}
\hline & \multicolumn{3}{|c|}{ Transaction in } & \multirow{2}{*}{ Total } \\
& \multicolumn{2}{|c|}{ MW } & Generation \\
\cline { 2 - 4 } & $\begin{array}{c}\text { To } \\
\text { B12 }\end{array}$ & To B16 & To B29 & (MW) \\
\hline From S2 & 10 & 5 & -- & 15 \\
\hline From S5 & 5 & 10 & 5 & 20 \\
\hline From S8 & 10 & 5 & 15 & 30 \\
\hline Total Load & 25 & 20 & 20 & 65 \\
(MW) & & & & \\
\hline
\end{tabular}

The actual line flows in all the lines due to above contract case, by proposed method and NR method arecompared in Fig.2. These transactions provide highest impact on flow in line number 1 connected between buses 1 and 2 (72.015 MW). The line number 30 between buses 18 and 19 has least impact $(0.682 \mathrm{MW})$ because the buses18 and 19 are not involved in the transaction case considered.

The cost allocated in 50-50 sharing policy and 30-70 sharing policy for both the contract cases are compared inFig.3. In both cases of cost sharing, the total cost recovered for the use of transmission network for transaction case- 1 is $4076.6 \$ / \mathrm{hr}$. Similarly for transaction case-2, the total cost recovered for the use of transmission network is $4642.2 \$ / \mathrm{hr}$. The total wheeling charges in case 2 increases because of the increase in total MW transacted in thiscase. The cost obtained by proposed method for these two transaction cases are almost similar to the cost calculatedby MM method.

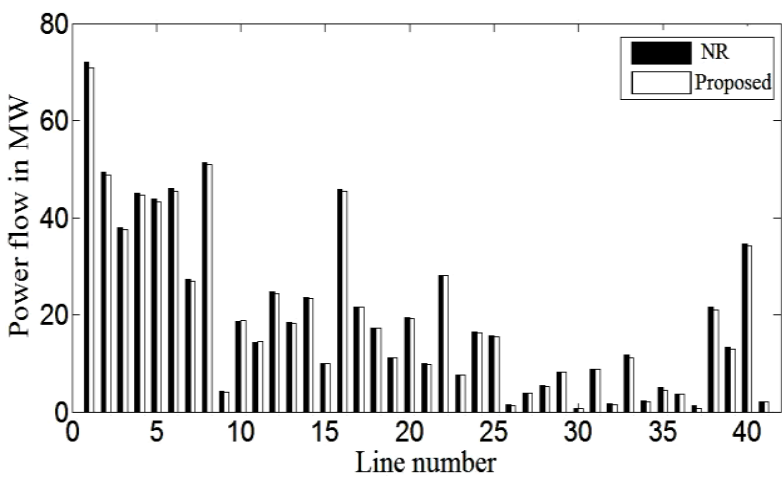

Fig. 2. Power flow by proposed method for transaction case 2 - IEEE 30 bus system

\section{CONCLUSION}

The developed Transaction impact factors relate the line flows with the magnitude of power transacted betweenthe selling and buying entities. The MM method to evaluate the transaction-related flows on all network lines, needsthe repeated power flow solution considering the nodal power injections only involved in that transaction. In theproposed method, once the TIFs are obtained for a given transaction, it does not require one to perform the powerflow solution to evaluate the transaction related power flows whenever any given different possible combinations oftransactions are exercised. Therefore, the proposed method is well suited for real time application. The mainadvantage of the developed method lies in its capability to consider multilateral transaction simultaneously. The costallocated to individual seller and buyer and the various schemes of cost sharing principle between seller and buyer are also provided. This helps in taking correct economic decision.

\section{REFERENCES}

[1] D.Shirmohammadi, Ch.Rajagopalan, E.R.Alward and C.L.Thomas, "Cost of transmission transactions: anintroduction", IEEE Trans. on Power Syst., vol.6, no.3, pp.1546-1560, 1991.

[2] J.W.Marangon Lima, "Allocation of transmission fixed charges: an overview", IEEE Trans. on Power Syst., vol.11,no.3, pp.14091418,1996

[3] J.Bialek, "Topological generation and load distribution factors for supplement charge allocation in transmissionopen access", IEEE Trans. on Power Syst.,vol.12, no.3, pp.1185-1193, 1997.

[4] D.kirschen,D.Ahmed,G.Strbac, "Allocating Transmission System Usage on the Basis of Traceable Contributions ofGenerators and Loads to Flows", IEEE Trans. on Power Syst.,vol.13, no.2, pp. 527-534, 1998

[5] F.D.Galiana,A.J.Conejo and H.A.Gil, "Transmission cost allocation based on equivalent bilateral exchanges", IEEETrans. on Power Syst., vol.18, no.3, pp.1425-1431, 2003.

[6] A.J.Conejo, J.Contreras, D.A.Lima, and A.Padilha-Feltrin,"Zbus transmission network cost allocation”, IEEE Trans. OnPower Syst., vol.22, no. 1, pp.342-349, 2007.

[7] K.L.Lo, M.Y.Hassan and S.Jovanovic, "Assessment of MW-mile method for pricing transmission services: anegative flow-sharing approach", IET Gener:, Transm. Distrib., vol.1, no.6, pp. 904-911, 2007.

[8] R.Kovacs and A.Leverett, 'A load flow based Method for Calculating Embedded, Incremental and Marginal cost oftransmission Capacity', IEEE Trans. on Power Syst., vol. 9, no. 1, pp. 272278,1994

[9] J.Pan, Y.Teklu and K.Jun, " Review of usage-based transmission cost allocation methods under open access", IEEETrans. on Power Syst., vol.15, no.4, pp. 1218-1224, 2000.

[10] A.J.Wood, B.F.Wollenberg, "Power generation, operation and control", Wiley, New York, 1984.

[11] http://www.ee. washington.edu/research/pstca.

\section{BIOGRAPHIES}

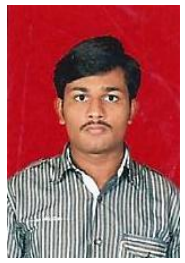

N.NARENDRA REDDY is pursuing Master of Technology in Electrical Power Systems Engineering from JNTUA College of Engineering Pulivendula-516390, Andhra Pradesh, India. $\mathrm{He}$ is presently working on his project under the guidance of Asst.Professor K.Vimala Kumar. 


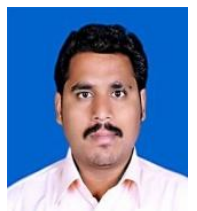

K.Vimala Kumar received the Master of Technology degree in Electrical \& Electronics Engineering from Jawaharlal Nehru Technological University Hyderabad, India 2008. He is a research student of Jawaharlal Nehru Technological University, Ananthapur, India. Currently he is working as Assistant Professor in the department of Electrical and Electronics Engineering, J.N.T.U.A College of Engineering, Pulivendula-516390, Andhra Pradesh, India. His interest areas are power system deregulation, power system peration and control, power system design and dynamic load modelling. 